\title{
The Drawing and the intuitive action on knowledge acquisition Empowering design though reasoning with drawing
}

Drawing as a reasoning tool empowers intuition when interacting with knowledge, in learning contexts, in high education settings, students achieve an improved experience with the subject of learning defying a superficial memorization and deepening the learning experience. Trough mental map drawings with points of access to information, students plan the subject of study through higher levels of contextualization. Those levels of contextualization trigger new reasoning actions enriching the intuitive retrieval of new information. drawing, learning, intuitive decision making, transcoding processes

\section{Introduction}

In classroom tuition as teachers, often we get in contact with learner's that become unmotivated with Learning subjects due to problems of reasoning. Unmotivated apart of other reasons due to a false notion of time required in comprehending and mastering a specific subject. The rhythm of contemporaneous society and the ephemeral idea retrieved from the everyday life undermine the students project notion on how to manage different activities to a defined outcome.

There is a need in developing a process amplifier of resilience able to offer a systematic approach in reasoning through drawing as a process and strategy able to empower a project development notion. Many studies explain how the drawing works as a reasoning tool when learning a process, the learner attempt to represent his comprehension on a specific subject. The act of drawing can work as stimulus; the learner interacts with the subject of study when attempting to sketch reasoning. Although the drawing is useful as a tool, it still lacks a stronger link with writing and talking. There is the need to empower the drawing as reasoning tool in a possible strategy applied to "learning to learn" finding new links and project other relations.

The empowerment of different skills is a direct result when applying new methods conceived to trigger and foster creativity in interpersonal levels. Helping someone to represent and communicate systems of reasoning is crucial in an age of reuse and adaptation of skill competences.

The better use of knowledge and rapid innovation requires a broadening of the creative skills base involving the whole population. Innovative capacity is closely linked with creativity as a personal attribute based on cultural and interpersonal skills and values, creativity and innovation in the personal, interpersonal and intercultural fields, including 
"mathematical competence and basic competences in science and technology", "digital competence", "learning to learn", "social and civic competences", "sense of initiative and entrepreneurship" and "cultural awareness and expression" (EU Commission, 2009).

Empowering the interpersonal communication and intuitive skills, joining drawing to Storytelling provides a possible link between the reasoning through drawing, talking writing and information management.

This metaphorical relation within this experimental approach relates with the everyday life experience, when students solve problems or define outcomes for their projects.

Relating with some ideas about drawing presented by Neal Lerner on the work of XIX century Louis Agassiz with students; Drawing is not only for students to demonstrate their content knowledge, the struggle continues between mastering facts and comprehending processes, between drawing to render and drawing to learn. The drawing presents the possibility to learning science as a dynamic and meaningful process (Lerner: 2007).

Reasoning through drawing and schematics can support the expression of an idea. In that system schematics help the learners structure the path and narrative elements in the storytelling sequence. This strategy can engage the learners in displaying their own structure and logic system.

As the authors Siu-Lan Tan and Megan E. Kelly refer; In the classroom Drawing has the power to enables the learners to improve their acuity over the object in study, allowing the teacher to detect evolutions in their acuity, observation made on their graphical annotations resultant from multiple exposures and interactions with the subject studied on the learning module (Tan, Kelly: 2004).

Drawing schematics relates not only with "visual shapes" but also with "functional structures" conceptual or technical in their nature. Helping the learner to discover his own structure of logic, empowers is self-confidence when is expressing an idea and promotes the transcoding practice by drawing along future Learning experiences.

When drawing, sketching or even doodling students exteriorize a stream of thoughts about something occurring in their inner thoughts and external stimulus, when following that graphic materialization they interact with the subject of knowledge, therefore they construct and develop their knowledge trough this sequence of inner reasoning and graphic expression. The Inner reasoning conducts the act of drawing, and the graphic expression, consequently the represented information suggests the reasoning of seeing.

The same action happens when someone ask students to explain something recently learned, through the effort of explaining something, they structure the idea and the information content, that effort will help them to better define the subject still in process of assimilation. This process is independent from the possible truthiness on the description.

In the link between talking and drawing the union of these streams of information consolidate the transformation required in a learning process containing drawing as a reasoning tool. To learn is to adapt, not only us to an exterior environment but also the new structures of fresh information to pre-existent or new inner structures of assimilation. Most thinkers concerned with comprehending human thought and action think it perfectly reasonable, even necessary, to postulate a system of mental representations. 
The existence of symbol systems and the indispensable role they play in our cognitive functioning is a fact apparent to all. Imagine a life without natural language, mathematical systems, the various forms of painting, sketching, drawing, musical notation, and so on (Goel: 2009).

The realm of learned fresh information differs from our functional reality, consequently after memorization there is an effort to adequate the new input to our own "systems of perception". In that sense the act of learning performs in several stages or levels, stimulus, memorization, appropriation and practice.

In our everyday interactions we are also allowed to build inner devices from the information gathered in the learning process, when expressing bits of raw information we give them meaning transforming information in working devices applied when developing new tasks in the near future. Through metaphors we under explain crucial but complex information. This occurs because information gets extremely simplified in order to become a black box concept, something trivial in our conversations, a "Lego" block applied in our communication but in minutia hard to explain.

We cannot comprehend the inner processes of a black box, but nonetheless we integrate their inputs and outputs into our decision-making (Tschäppeler, Krogerus: 2011). From this translation process results also a reflection on both the way we convey the idea of thought in the contemporaneous society and how it will influence other's not only on their reading methods but in the way they process thinking.

Problem structuring is the process of drawing on knowledge from various sources to compensate for missing information in the problem statement and using this knowledge to contract the problem space (Simon: 1973) In contracting the "problem Space" the metacognition works other solutions in individual and interpersonal settings.

Metacognition refers to the cognitive control and monitoring of all sorts of cognitive processes like perception, action, memory, reasoning or emoting. Metacognition relate with certain moments and specific needs, some of them more conscious related with external variables. The building blocks responsible for constructing the evolving story of who we are across time are tagged with locations where they were formed, emotionally jarring memories adhere to this tag with particular determination, these tags bind events to the places (Alter: 2013).

To develop the metacognition, there's a need in opening new channels, intersect information and awake our conscious interest on how our devices of information process ideas. Such a complex phenomenon can't be mastered easily and the accessible action must embrace playful approaches. Playful on the grounds that the ludic approach allows a fast engagement and the levels of frustration on results will maintain low, the "interface" does not represent a barrier in producing and developing future ideas. Focusing on the interface is crucial when embracing the design of a personal mental production system. Metacognition applied in practice, puts in question standard and taught systems in creating and managing thought, at the end, all successive questions logically derives in different expression systems.

Creating new strategies in conceiving ideas result in a prism metaphor, working as input the stimulus, the light source, and the idea not yet defined in a recognizable shape. The prismatic device and his structure break down the input into a spectrum with several 
layers, creating an array system able to operate and reason different levels of reality.

The system developed to process and reason information results from repeating the same approach to the object of study, time after time till there is a conscience about the reasoning system. A system created by a survival mechanism where the individual thought creates a balanced system of thinking influenced by external settings. Those external factors stimulate an intuitive response. The same kind of response will originate a phenomenon similar with the persistence of image on the cinematic moving image. Each response works as layer, after several picture overlays, evolved through time, the persistence of image ends suggesting a recognizable shape to the viewer.

When modifying the view on the process students implement several changes, this sculpture allows an interpretation as a creative product, so in that manner, reasoning transforms itself in a product with creative extensions. Creative elements are stimulated by elements by their environment close social scope, fields of interest and the overall dynamic in the contextual system. Creative products are possible by a close intertwined and interactive system of social networks and fields of study (Sternberg: 1999).

While addressing this situation in the learning context, teachers comprehend the process of reasoning with different creative extensions, and guided by different decision making processes. There are various decision making processes, analytical and intuitive that appear to be mediated by different processes or systems (Ross et al: 2004; Evans: 2008; Kahneman \& Klein: 2009).

Reasoning with intuition is linked to uncertainty. Analogies and mental simulations could clarify conditions of uncertainty. Ball (2009) propose that analogizing and mental simulation are strategies deployed to resolve uncertainty - a claim that is supported by the fact that uncertainty levels returned to baseline values at the end of analogizing and simulation episodes. Ball (2009) consider "Analogical reasoning involves accessing and transferring previously acquired knowledge of objects, attributes and relations to support current problem solving and decision making activities".

Processes that reflect a sequential, step-by-step, methodical, and time-consuming process mediate analytical decision-making. In distinction, intuitive decision-making relies upon a more holistic approach inprocessing to continue judging for planned results as the external problem space changes (Evans: 2008). Intuition is a rapid, non-conscious, indication to the existence of meaningful information detected through one or more sensory modalities (Luu et al: 2010).

Intuition allows information extracted by automatic sensory processes, which operate on the time scale of 100's of milliseconds, to be organized by pre-existing (top-down) knowledge. This unconscious organization of incoming information may elicit a feeling or impression of a solution (Luu et al: 2010), which introduces insight or a rapid awareness.

According to Bowers et al. (1990) intuition can guide the judgment process by helping with the discovery of credible solutions from which to choose. This characterization of intuition, and others that result from it, assumes a high level of familiarity with the information being detected. Until recently, intuitive decision-making was assumed to require important domain knowledge (Kahneman \& Klein: 2009). However a growing number of results ranging from the biological (mainly, neural) to the cognitive (Lieberman: 2000; Jung-Beeman et al: 2004; Luu et al: 2010) suggest that pre-existing expertise, 
which requires years of practice to achieve (Dreyfus \& Dreyfus: 1980; Ericsson et al: 1993) may not be a key requirement for intuitive decision-making processes. These studies, and others, suggest that intuitive decision making processes share some of the same underlying neural structures and cognitive processes as a type of learning known as implicit learning (Lieberma: 2000, 20007; Kaufman et al: 2010). According to these authors, therefore, through the acquisition of domain awareness through implicit learning, one may be able automatically strength the neural, cognitive and behavioral levels, the same characteristics needed for effective intuitive decision making intuitive.

\section{Conclusion}

Intuition plays a crucial role on drawing as a reasoning tool not only in relation with external variables but also acting on thought and therefore performing a metacognition process. The implicit structure present in some background processes assisting the project design development and reasoning unveils a new importance under the view of metacognition processes operated by intuitive parameters.

Incorporating Drawing as a strengthening tool of reasoning plays a significant role in triggering new approaches to reasoning trough scaled contextualization. Drawing promotes during the process of multiple scanning's, different perspectives on information visualization and delivers different comprehensions over a design project elaboration and sequence. In the end, drawing plays a significant role in the process of our inner journey in "learning to learn".

\section{References}

Ainsworth, Prain, Tytler, Shaaron, Vaughan, Russell, (2011) Drawing to Learn in Science. Sciencemag.org, 33, 1096-1097

Alter, A. (2013) Drunk Tank Pink: And Other Unexpected Forces that Shape How We Think, Feel, and Behave. Penguin Group

Ball, L.J. and Christensen, B.T. (2009) Analogical reasoning

and mental simulation in design: two strategies linked to uncertainty resolution. Design Studies 30, 2, 169-186.

Chambre, P., Izaute, M., Marescaux, PJ. (2002) Metacognition: Process, Function, and Use. Springer

Dreyfus, H.C. \& Dreyfus, S.E. (1980) A five-stage model of the mental activities involved in directed skill acquisition. ORC 80-2 (F49620-79-C-0063). Bolling, AFB, Washington, DC. Air Force Office of Scientific Research: United States Air Force.

Evans, J. (2008) Dual-processing accounts of reasoning, judgment, and social cognition. Ann Rev Psyc, 59, 255-278.

Ericsson, K.A., Krampe, R. Th., and Tesch-Romer, C., (1993) The role of deliberate practice in the acquisition of expert performance. Psychological Review, 700, p. 379 and p. 384 EU Commission (2008) "Explanatory Memorandum concerning the European Year of Creativity and Innovation 2009". Brussels Goel, V. (1995) Sketches of thought: Massachusetts: MIT Press. Lerner, Neal, (2007) Legacies of Agassiz. J. Technical writing and communication, Vol. $37(4), 379-394$

Lieberman, M.D. (2000). Intuition: A social cognitive neuroscience approach. Psychological Bulletin, 126(1): 109-137.

Lieberman, M. D. (2007). Social cognitive neuroscience: A review of core processes. Annual Review of Psychology, 58, 259-289. 
Luu, P., Geyer, A., Wheeler, T., Campbell, G., Tucker, D., \& Cohn, J. (2010). The Neural Dynamics and Temporal Course of Intuitive Decisions. (In Press) Public Library Of Science. Kaufman, A. B., Kornilov, S. A., Bristol, A. S., Tan, M., \& Grigorenko, E. L. (2010) The neurobiological foundation of creative cognition. In J. C. Kaufman \& R. J. Sternberg (Eds.), The Cambridge handbook of creativity (pp. 216-232). New York: Cambridge University Press.

Ross, K., Klein, G, Thunholm, P, Schmitt, J. \& Baxter, H.C. (2004). The Recognition-Primed Decision Model. Mil Rev p. 6-10.

Simon, H. A. (1973) The Structure of III-Structured Problems. Artificial Intelligence 4:181-201 Sternberg, R. (1999) Handbook of creativity. Cambridge: Cambridge University Press. Kahneman , D., Klein, G. (2009) "Conditions for intuitive expertise: A failure to disagree". Am. Psyc. Vol 64(6). P. 515-526.

Tan, E. K., Siu-Lan, M. (2004) "Graphic Representations of Short Musical Compositions". Psychology of Music, 32, 191-212

Tschäppeler, R., Krogerus, M. (2011) The Decision Book: Fifty Models for Strategic Thinking. Profile Books 